\title{
Translationally controlled tumour protein is associated with podocyte hypertrophy in a mouse model of type 1 diabetes
}

\author{
D. K. Kim • B. Y. Nam • J. J. Li • J. T. Park • S. H. Lee • \\ D. H. Kim • J. Y. Kim • H. Y. Kang • S. H. Han • \\ T. H. Yoo • D. S. Han • S. W. Kang
}

Received: 24 October 2011 / Accepted: 31 December 2011 /Published online: 4 February 2012

(C) Springer-Verlag 2012

\begin{abstract}
Aims/hypothesis Translationally controlled tumour protein (TCTP) is thought to be involved in cell growth by regulating mTOR complex 1 (mTORC1) signalling. As diabetes characteristically induces podocyte hypertrophy and $\mathrm{mTORC} 1$ has been implicated in this process, TCTP may have a role in the pathogenesis of diabetes-induced podocyte hypertrophy.

Methods We investigated the effects and molecular mechanisms of TCTP in diabetic mice and in high glucose-stimulated cultured podocytes. To characterise the role of TCTP, we conducted lentivirus-mediated gene silencing of TCTP both in vivo and in vitro.

Results Glomerular production of TCTP was significantly higher in streptozotocin induced-diabetic DBA/2J mice than
\end{abstract}

D. K. Kim and B. Y. Nam contributed equally to this study.

Electronic supplementary material The online version of this article (doi:10.1007/s00125-012-2467-7) contains peer-reviewed but unedited supplementary material, which is available to authorised users.

D. K. Kim · J. Y. Kim

Department of Internal Medicine,

Seoul National University Hospital,

Seoul, Korea

B. Y. Nam • J. T. Park - S. H. Lee - D. H. Kim $\cdot$ H. Y. Kang

S. H. Han $\cdot$ T. H. Yoo $\cdot$ D. S. Han $\cdot$ S. W. Kang $(\bowtie)$

Department of Internal Medicine, College of Medicine,

Brain Korea 21, Severance Biomedical Science Institute,

Yonsei University,

134 Shinchon-Dong, Seodaemoon-Gu,

Seoul, Korea 120-752

e-mail: kswkidney@yumc.yonsei.ac.kr

J. J. Li

Nephrology and Dialysis Unit, Department of Internal Medicine,

The Affiliated Hospital, YanBian University Medical College,

Jilin, People's Republic of China in control animals. Double-immunofluorescence staining for TCTP and synaptopodin revealed that podocyte was the principal cell responsible for this increase. TCTP knockdown attenuated the activation of mTORC1 downstream effectors and the overproduction of cyclin-dependent kinase inhibitors (CKIs) in diabetic glomeruli, along with a reduction in proteinuria and a decrease in the sizes of podocytes as well as glomeruli. In addition, knockdown of TCTP in $d b / d b$ mice prevented the development of diabetic nephropathy, as indicated by the amelioration of proteinuria, mesangial expansion, podocytopenia and glomerulosclerosis. In accordance with the in vivo data, TCTP inhibition abrogated high glucose-induced hypertrophy in cultured podocytes, which was accompanied by the downregulation of mTORC1 effectors and CKIs.

Conclusions/interpretation These findings suggest that TCTP might play an important role in the process of podocyte hypertrophy under diabetic conditions via the regulation of mTORC1 activity and the induction of cell-cycle arrest.

Keywords Diabetic nephropathy · Hypertrophy · Mouse · mTOR complex $1 \cdot$ Podocyte $\cdot$ TCTP

$\begin{array}{ll}\text { Abbreviations } \\ \text { AII } & \text { Angiotensin II } \\ \text { ARB } & \text { Angiotensin II receptor blocker } \\ \text { CKIs } & \text { Cyclin-dependent kinase inhibitors } \\ \text { DN } & \text { Diabetic nephropathy } \\ \text { dTBP2 } & \text { Dimerised TCTP-binding peptide-2 } \\ \text { 4EBP1 } & \text { Eukaryotic elongation factor 4E-binding- } \\ & \text { protein-1 } \\ \text { EGFP } & \text { Enhanced green fluorescent protein } \\ \text { ERK } & \text { Extracellular signal-regulated kinase } \\ \text { GBM } & \text { Glomerular basement membrane }\end{array}$




$\begin{array}{ll}\text { GEF } & \text { Guanine-nucleotide-exchange factor } \\ \mathrm{HG} & \text { High glucose } \\ \text { mTORC1 } & \text { mTOR complex 1 } \\ \mathrm{NG} & \text { Normal glucose } \\ \mathrm{N}_{\mathrm{P} / \mathrm{G}} & \text { Number of podocytes/glomerulus } \\ \mathrm{ND}_{\mathrm{P} / \mathrm{G}} & \text { Numerical density of podocyte/glomerulus } \\ \mathrm{p} 70 \mathrm{~S} 6 \mathrm{~K} & \mathrm{p} 70 \mathrm{~S} 6 \text { kinase } \\ \mathrm{Rheb} & \text { Ras homologue enriched in brain } \\ \mathrm{TCTP} & \text { Translationally controlled tumour protein } \\ \mathrm{VF}_{\mathrm{MES} / \mathrm{G}} & \text { Volume fraction of mesangium/glomerulus } \\ \mathrm{VF}_{\mathrm{P} / \mathrm{G}} & \text { Volume fraction of podocytes/glomerulus } \\ \mathrm{V}_{\mathrm{G}} & \text { Glomerular volume } \\ \mathrm{V}_{\mathrm{MES} / \mathrm{G}} & \text { Mesangial volume/glomerulus } \\ \mathrm{V}_{\mathrm{P}} & \text { Podocyte volume }\end{array}$

\section{Introduction}

Diabetic nephropathy (DN) is characterised by glomerular hypertrophy, which is partly due to hypertrophy of glomerular cells including podocytes [1]. Until recently, podocyte hypertrophy in DN was thought to be merely a compensatory phenomenon to cover the denuded glomerular basement membrane (GBM) due to podocyte loss following injury [2]. However, mounting evidence indicates that the density of the podocytes, rather than their absolute numbers, is reduced in the early stage of DN in humans [3], as well as in an experimental diabetic model [4]. This suggests that the mechanical load in podocytes due to glomerular hypertrophy may cause adaptive growth and cellular injury $[5,6]$. In addition, the spontaneous hypertrophy of podocytes that precedes other structural changes in DN has been indentified in a recent morphometric analysis [7], suggesting that podocyte hypertrophy is a prominent early feature of $\mathrm{DN}$ that is independent of other pathological changes. Therefore, understanding the pathogenesis of podocyte hypertrophy may be a major challenge to the treatment of DN.

Diabetes-induced podocyte hypertrophy requires $G_{1} / S$ cell-cycle arrest mediated by cyclin-dependent kinase inhibitors (CKIs) [5, 8]. In addition, the activation of mTOR complex 1 (mTORC1) and its downstream effectors, including eukaryotic elongation factor 4E-binding-protein-1 (4EBP1) and p70S6 kinase (p70S6K), play a pivotal role in diabetes-induced podocyte hypertrophy $[9,10]$.

Translationally controlled tumour protein (TCTP) plays a role in various intracellular functions, including cell growth [11]. Although the precise mechanisms by which TCTP regulates cell growth remain elusive, TCTP may induce cellular hypertrophy through the mTORC1 pathway [12-14]. Because glomerular cell hypertrophy is a characteristic of DN, TCTP may play an important role in cellular hypertrophy through the activation of mTORC1 signalling. However, the role of TCTP under diabetic conditions has not been characterised. Therefore, we examined changes in TCTP production in diabetic glomeruli and quantified the impact of TCTP on the sizes of podocytes and glomeruli. The signalling pathway that regulates podocyte hypertrophy was also investigated.

\section{Methods}

Generation of Tctp shRNA-expressing lentivirus According to the mouse cDNA sequence of Tctp, three siRNA target sites were selected using the siRNA Selection Web Server (http://jura.wi.mit.edu/bioc/siRNA). In addition, a scrambled sequence was created as a control (electronic supplementary material [ESM] Table 1). The annealed oligonucleotides were inserted into the BstBI-BbsI sites of the pCMV-U6 vector (a gift from P. Osten, Northwestern University, Feinberg School of Medicine) [15]. The PCR-positive samples were sequenced and named pCMV-U6-TctpshRNA-1,2,3 and scrambled. The U6-TctpshRNA cassettes were recloned into the lentiviral vector FUGW (P. Osten) [15] using NheI/BstBI. Lentiviruses were produced as previously described [16]. A TCTP construct was also generated by PCR with the following primers: 5'-AACCGCTAGATCTATGATCATCTACCGG GACATA-3' and 5'-AGGCCGGTCGACTTAACATTTCTC CATCTCTAAGCC-3'. This construct was cloned into penhanced green fluorescent protein (EGFP)-C1 (BD Biosciences, Franklin Lakes, NJ, USA), resulting in the vector pEGFP-C1-Tctp.

Experimental protocols All animal studies were conducted using approved protocols and carried out in accordance with the Principles of Laboratory Animal Care (NIH Publication no. 85-23, revised 1985). Male DBA/2J mice (Jackson Laboratories, Bar Harbor, ME, USA) weighing 24-26 g were injected with either the diluent or streptozotocin (40 $\mathrm{mg} \mathrm{kg}^{-1} \mathrm{day}^{-1}$ ) intraperitoneally for 5 consecutive days. Diabetes was confirmed by blood glucose levels above $16.65 \mathrm{mmol} / 1$ on the third day after the last injection. After the confirmation of diabetes (day 0 ), diabetic mice were randomly allocated ( $n=8$ per group) for treatment with PBS (DM), LV-scr (DM+LV-scr) or LV-shTctp1 (DM+LVshTctp1). Similarly, non-diabetic mice were assigned to one of three groups ( $n=8$ per group) and were injected with PBS (C), LV-scr (C+LV-scr) or LV-shTctp1 (C+LV-shTctp1). The animals were given the selected treatment on days 0 and 7 via hydrodynamic tail vein injection as described previously [17]. Briefly, mice were maintained under isoflurane anaesthesia and given injections into the tail vein within $10 \mathrm{~s}$ of $1 \mathrm{ml}$ of PBS alone or PBS containing $4 \times 10^{8} \mathrm{TU}$ of lentivirus. Mice were killed at 6 weeks after the first injection of lentivirus or PBS. 
To elucidate the role of TCTP in long-term changes, 6week male $d b / d b$ mice (C57BLKS/J-lepr ${ }^{\mathrm{db}} /$ lepr $\left.^{\mathrm{db}}\right)$ and their non-diabetic control $d b / m$ mice (C57BLKS/J-lepr ${ }^{\mathrm{db} / \mathrm{m}}$ ) were purchased from Jackson Laboratories, then treated with PBS, LV-scr or LV-shTctp 1 at 7 and 8 weeks of age using the same method done with the DBA/2J mice, and were killed at 28 weeks of age.

Detection of integrated lentivirus To detect tissue integration of the lentiviral vector that contains the EGFP as a reporter, a semi-nested PCR using EGFP-specific primers (ESM Table 2) was performed with genomic DNA extracted from the liver, spleen, lung, heart, brain and kidney.

ELISA for EGFP The EGFP concentrations were measured by ELISA as previously described [18] (see ESM Methods).

Biochemical analyses AER was measured by ELISA. The urinary sodium, serum and urinary creatinine levels were measured by enzymatic method.

ELISA for TCTP The levels of TCTP were measured in mouse plasma and urine, and cell culture media using a commercial ELISA kit (USCN Life, Wohan, People's Republic of China).

Morphometric analyses The glomerular volume $\left(\mathrm{V}_{\mathrm{G}}\right)$ was determined as described previously [19]. The numerical density $\left(\mathrm{ND}_{\mathrm{P} / \mathrm{G}}\right)$ and number of podocytes/glomerulus $\left(\mathrm{N}_{\mathrm{P} / \mathrm{G}}\right)$ were estimated with an unbiased stereological technique using an optical dissector $[7,20]$. Podocyte nuclei in the reference section that were not present in the look-up section were counted $\left(\mathrm{Q}_{\mathrm{P}}{ }^{-}\right)$. The $\mathrm{ND}_{\mathrm{P} / \mathrm{G}}$ was calculated as $\Sigma \mathrm{Q}_{\mathrm{P}}{ }^{-} /\left(\Sigma \mathrm{A}_{\mathrm{G}} \times \mathrm{h}\right)$, where $\mathrm{h}$ is the distance between sections with a value of $1.5 \mu \mathrm{m}$. $\mathrm{N}_{\mathrm{P} / \mathrm{G}}$ was calculated as $\mathrm{ND}_{\mathrm{P} / \mathrm{G}} \times \mathrm{V}_{\mathrm{G}}$. The volume fractions of podocytes/glomerulus $\left(\mathrm{VF}_{\mathrm{P} / \mathrm{G}}\right)$ and mesangium/ glomerulus $\left(\mathrm{VF}_{\mathrm{MES} / \mathrm{G}}\right)$ were measured at each section level with a point-counting method. The podocyte volume $\left(\mathrm{V}_{\mathrm{P}}\right)$ and mesangial volume/glomerulus $\left(\mathrm{V}_{\mathrm{MES} / \mathrm{G}}\right)$ were estimated as $\mathrm{VF}_{\mathrm{P} / \mathrm{G}} / \mathrm{ND}_{\mathrm{P} / \mathrm{G}}$. and $\mathrm{VF}_{\mathrm{MES} / \mathrm{G}} \times \mathrm{V}_{\mathrm{G}}$ respectively. The degree of glomerulosclerosis was assessed using a semi-quantitative score as described previously [21] (see ESM Methods).

Immunofluorescence For double-immunofluorescence staining, $4 \mu \mathrm{m}$ frozen sections stained with monoclonal antibody to TCTP (MBL International, Woburn, MA, USA) and Cy2conjugated anti-mouse IgG antibody (Research Diagnostics, Flanders, NJ, USA) were further incubated with monoclonal rat anti-CD31, monoclonal rat anti-Thy1.1 (Abcam, Cambridge, UK) or polyclonal goat anti-synaptopodin antibody (Santa Cruz Biotechnology, Santa Cruz, CA, USA), followed by the appropriate fluorescent secondary antibodies.
TUNEL assay Apoptosis was assessed by TUNEL staining. TUNEL-positive cells were recognised as podocytes if the cells resided on the outer aspect of the GBM.

Electron microscopy Four $1 \mathrm{~mm}^{3}$ samples of the renal cortex of each mouse were embedded in epoxy resin. The appropriate areas were stained with uranyl acetate and lead citrate before electron microscopy (JEM-1400, JEOL, Tokyo, Japan).

Glomerular isolation Glomeruli were isolated by a sieving technique as described previously [22].

Podocyte culture Conditionally immortalised mouse podocytes (a gift from P. Mundel, School of Medicine, University of Miami) were cultured as previously described [23] (see ESM Methods). After confirming differentiation, $4 \times 10^{5} \mathrm{TU}$ of lentivirus suspension was added to each well. Lentiviraltransduced or non-transduced podocytes were serum restricted for $24 \mathrm{~h}$, after which the medium was changed to RPMI containing normal glucose (NG, $5.6 \mathrm{mmol} / \mathrm{l}), \mathrm{NG}+$ $24.4 \mathrm{mmol} / \mathrm{l}$ mannitol $(\mathrm{NG}+\mathrm{MN}), \mathrm{NG}+10^{-6} \mathrm{~mol} / \mathrm{l}$ angiotensin II (NG+AII), high glucose ( $\mathrm{HG}, 30 \mathrm{mmol} / \mathrm{l})$ or $\mathrm{HG}^{+}$ $10^{-7} \mathrm{~mol} / \mathrm{l} \mathrm{L}-158809$ (HG+angiotensin II receptor blocker [ARB]). To elucidate the effects of extracellular TCTP, cultured podocytes were exposed to NG media containing recombinant TCTP (rTCTP) $(0,0.5,1,10 \mu \mathrm{g} / \mathrm{ml})$ (Novus Biologicals, Littleton, CO, USA) and to HG media containing $0.5 \mu \mathrm{M}$ of dimerised TCTP-binding peptide-2 (dTBP2) that inhibits the cytokine-like effects of TCTP (a gift from K. Lee, College of Pharmacy, Ewha Womans University) [24].

Assessment of hypertrophy in cultured podocytes Hypertrophy of the cultured podocytes was assessed from the cellular protein/cell counts and by flow cytometry (see ESM Methods).

Real-time PCR Total RNA extracted from sieved glomeruli and podocytes were reverse transcribed (see ESM Methods). The primers used for TCTP, fibronectin, type IV collagen and $18 \mathrm{~s}$ amplifications are listed in ESM Table 2.

Western blot analysis Western blots were performed using antibodies against TCTP (MBL International), phospho4EBP1, 4EBP1, phospho-p70S6K, p70S6K, active caspase-3 (Cell Signaling, Beverly, MA, USA), fibronectin (Dakocytomation, Glostrup, Denmark), type IV collagen (SouthernBiotech, Birmingham, AL, USA), p27, p21, EGFP or $\beta$-actin (Santa Cruz Biotechnology) (see ESM Methods).

Statistical analysis All values are expressed as the mean \pm SEM. $p<0.05$ was considered significant (see ESM Methods). 


\section{Results}

Gene-silencing efficiency To test the gene-silencing efficiency of the shRNA, COS7 cells were co-transduced with pEGFP-C1-Tctp and pCMV-U6-TctpshRNA-1,2,3 or scrambled. After 2 days, a significant reduction in the green fluorescent signals was found in cells transduced with pCMV-U6-TctpshRNA-1 and 3, and these results were further confirmed by western blotting (ESM Fig. 1a, b). The cultured podocytes were then incubated for 2 days with lentiviruses generated with these vectors. LV-shTctp 1 inhibited endogenous TCTP protein production more efficiently than LV-shTctp3 (ESM Fig. 1c). Therefore, the subsequent experiments were performed with LV-shTctp 1 or LV-scr.

In vivo transduction efficiency To test the in vivo transduction efficiency, we performed a hydrodynamic tail vein injection of LV-shTctp1, LV-scr or PBS into additional DBA/2J mice two times with a 1 -week interval ( $n=4$ per group). EGFP production as assessed by semi-nested PCR was highest in the liver and spleen, but also detected in the kidney at 6 weeks after the first injection (ESM Fig. 2a). In addition, immunostaining revealed that EGFP was produced in the glomeruli and tubulointerstitium of lentivirus-injected mice but not in those of PBS-injected mice at 2 and 6 weeks (ESM Fig. 2b). Additionally, the EGFP concentration in kidney lysates measured by ELISA persisted over the 6-week period (ESM Fig. 2c).

Animal data of $D B A / 2 J$ mice The ratios of kidney/body weight in DM and DM+LV-scr mice were significantly higher than in $\mathrm{C}$ or $\mathrm{C}+\mathrm{LV}$-scr mice. In contrast, the ratio was significantly lower in $\mathrm{DM}+\mathrm{LV}$-shTctp 1 mice than in $\mathrm{DM}$ or $\mathrm{DM}+\mathrm{LV}$-scr mice. Compared with the $\mathrm{C}$ group, 24-h AER was significantly higher in DM mice, and LVshTctp 1 transduction partly reversed this increase. Meanwhile, LV-shTctp 1 transduction in control mice did not affect the levels of AER. The urine sodium/creatinine ratios were significantly higher in all groups with diabetes than in $\mathrm{C}$ mice, but TCTP knockdown did not significantly affect the ratio (Table 1 ).
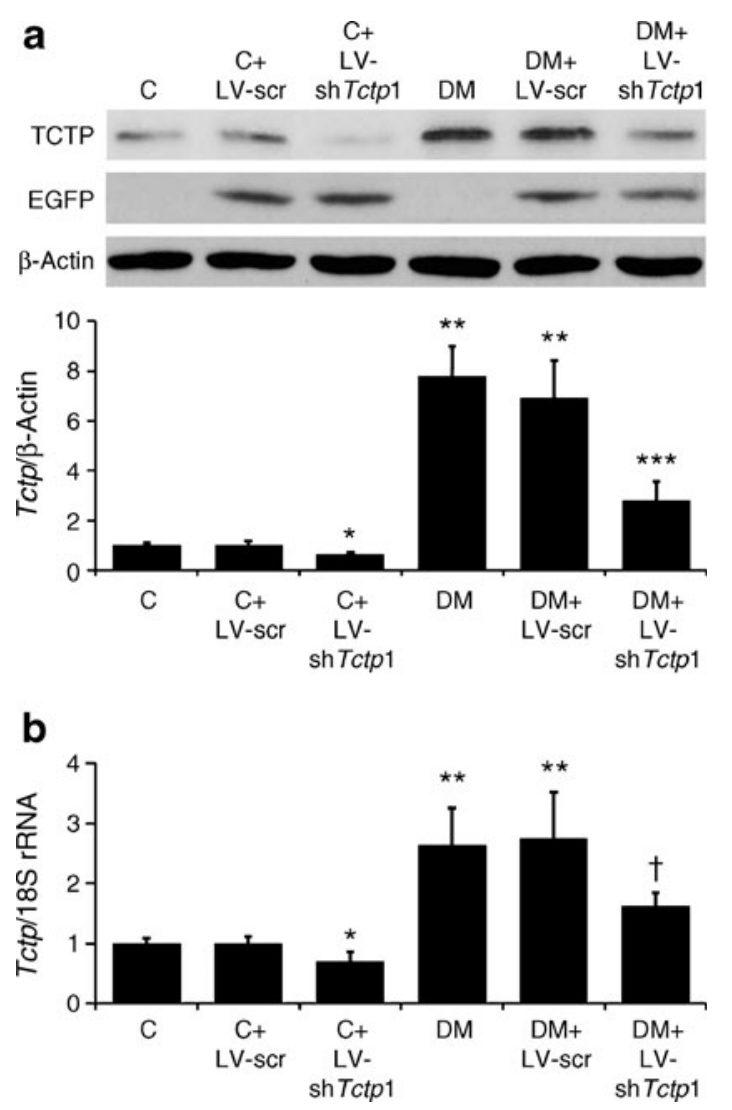

Fig. 1 Glomerular production of TCTP and in vivo gene silencing. a A representative western blot of TCTP in $\mathrm{C}, \mathrm{C}+\mathrm{LV}$-scr, $\mathrm{C}+\mathrm{LV}$ shTctp $1, \mathrm{DM}, \mathrm{DM}+\mathrm{LV}$-scr and $\mathrm{DM}+\mathrm{LV}$-shTctp 1 glomeruli (representative of four blots). Glomerular TCTP protein production was significantly higher in DM mice than in C mice (7.8-fold), and LV-shTctp1 treatment significantly reduced TCTP protein production in both the $\mathrm{C}$ and DM glomeruli by $38.0 \%$ and $64.1 \%$ respectively. LV-scr did not induce any significant change in the production of TCTP. The production of EGFP served as a lentiviral transduction control. ${ }^{*} p<0.05$ vs $\mathrm{C}$ and $\mathrm{C}+\mathrm{LV}$-scr groups; ${ }^{* *} p<0.01$ vs $\mathrm{DM}$ and $\mathrm{DM}+\mathrm{LV}$-scr group; ${ }^{* * * *} p<0.001$ vs $\mathrm{C}$ and $\mathrm{C}+\mathrm{LV}$-scr groups. b Tctp mRNA expression in sieved glomeruli. The expression pattern of the Tctp mRNA was similar to that of the protein. ${ }^{*} p<0.05$ vs $\mathrm{C}$ and $\mathrm{C}+\mathrm{LV}$-scr groups; ${ }^{* *} p<0.01$ vs $\mathrm{C}$ and $\mathrm{C}+\mathrm{LV}$-scr groups; ${ }^{\dagger} p<0.05$ vs DM and $\mathrm{DM}+\mathrm{LV}$-scr group. Data are means \pm SEM

Table 1 Animal data on control and streptozotocin induced-diabetic DBA/2J mice at 6 weeks after treatment

\begin{tabular}{|c|c|c|c|c|c|c|}
\hline Variable & $\mathrm{C}$ & $\mathrm{C}+\mathrm{LV}$-scr & $\mathrm{C}+\mathrm{LV}-\mathrm{sh} T c t p 1$ & $\mathrm{DM}$ & $\mathrm{DM}+\mathrm{LV}$-scr & $\mathrm{DM}+\mathrm{LV}$-shTctp 1 \\
\hline Body weight (g) & $31.4 \pm 3.2$ & $30.5 \pm 3.0$ & $29.8 \pm 3.1$ & $25.3 \pm 2.1$ & $24.9 \pm 3.1$ & $25.5 \pm 2.4$ \\
\hline Kidney/body weight (\%) & $0.70 \pm 0.11$ & $0.72 \pm 0.13$ & $0.73 \pm 0.09$ & $0.98 \pm 0.11^{* *}$ & $0.97 \pm 0.10^{* *}$ & $0.80 \pm 0.08^{*}$ \\
\hline Blood glucose $(\mathrm{mmol} / \mathrm{l})$ & $6.22 \pm 0.31$ & $6.61 \pm 0.27$ & $6.83 \pm 0.40$ & $27.68 \pm 2.58^{* *}$ & $26.37 \pm 2.29^{* *}$ & $26.09 \pm 2.70$ \\
\hline 24-h AER ( $\mu \mathrm{g} /$ day) & $27.3 \pm 10.7$ & $29.1 \pm 13.0$ & $29.3 \pm 12.1$ & $228.5 \pm 59.2^{* *}$ & $212.7 \pm 68.1^{* *}$ & $168.3 \pm 42.7^{*}$ \\
\hline $24-\mathrm{h} \mathrm{U}_{\mathrm{Na}} / \mathrm{U}_{\text {Creatinine }}(\mathrm{mmol} / \mathrm{mmol})$ & $16.1 \pm 5.2$ & $19.4 \pm 6.0$ & $15.1 \pm 9.6$ & $32.2 \pm 7.9^{* *}$ & $34.9 \pm 9.8^{* *}$ & $32.9 \pm 8.8^{* *}$ \\
\hline Creatinine clearance $\left.\left(\mu 1 \min ^{-1} \text { [g body weight }\right]^{-1}\right)$ & $12.7 \pm 2.4$ & $12.8 \pm 2.7$ & $12.4 \pm 2.8$ & $14.9 \pm 3.5$ & $14.6 \pm 3.2$ & $13.1 \pm 2.9$ \\
\hline
\end{tabular}

Data are mean $\pm \operatorname{SEM}(n=8$ per group)

${ }^{*} p<0.05$ vs DM mice; $* * p<0.01$ vs C mice 
Glomerular production of TCTP and in vivo gene-silencing Glomerular TCTP protein levels were significantly higher in $\mathrm{DM}$ and $\mathrm{DM}+\mathrm{LV}$-scr mice than in $\mathrm{C}$ and $\mathrm{C}+\mathrm{LV}$-scr mice. Densitometric quantification revealed that LV-shTctp 1 treatment significantly reduced TCTP production in both control and diabetic glomeruli. EGFP was only produced in glomeruli from lentivirus-injected mice (Fig. 1a). Tctp mRNA expression exhibited a similar pattern to that for protein production (Fig. 1b).

Localisation of TCTP production To identify the cell types responsible for TCTP overproduction in DM glomeruli, kidney tissues were double-stained for TCTP and cell type-specific markers for podocyte (synaptopodin), mesangial

\section{a}
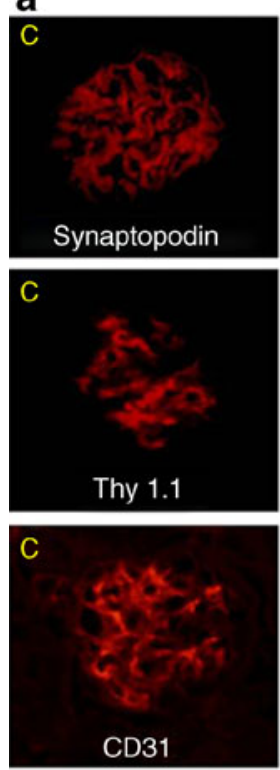

C
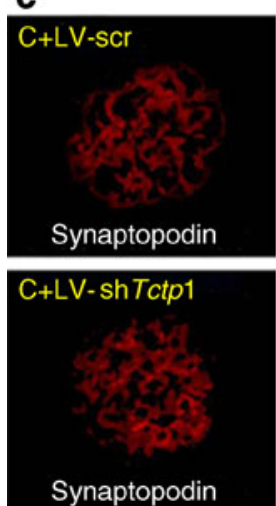
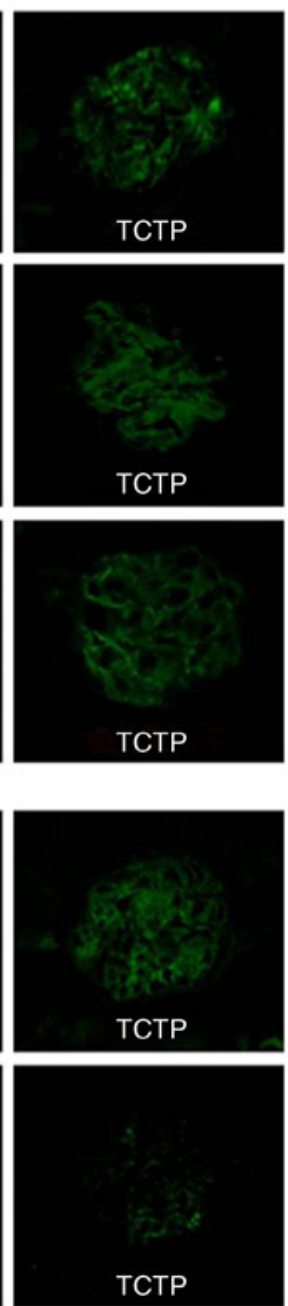
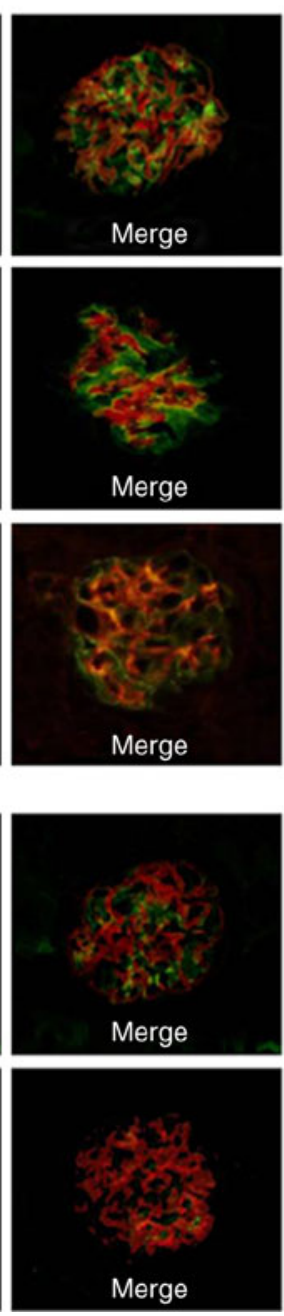

Fig. 2 Double-immunostaining microscopic images of TCTP (green) and cell type-specific markers for podocyte (synaptopodin, red), mesangial cell (Thy1.1, red) or endothelial cell (CD31, red). a In C glomeruli, TCTP appeared to colocalise with all three cell types (yellow). b Compared with $\mathrm{C}$ glomeruli, the intensity of the immunofluorescence for TCTP was increased in DM glomeruli. Doubleimmunofluorescence staining revealed that the increase in TCTP protein cell (Thy1.1) or endothelial cell (CD31). TCTP colocalised with all of the cell types examined in C glomeruli (Fig. 2a). In contrast, the intensity of TCTP immunofluorescence and its colocalisation signal with synaptopodin were greater in DM and DM+LV-scr glomeruli (Fig. 2b, c). These results indicate that podocytes were primarily responsible for the increase. In contrast, LV-shTctp 1 transduction in diabetic mice markedly reduced the signal for TCTP and its colocalisation with synaptopodin (Fig. 2c).

Morphological changes Light microscopy revealed a marked glomerular hypertrophy in DM and DM+LV-scr groups when compared with $\mathrm{C}$ and $\mathrm{C}+\mathrm{LV}$-scr groups. In contrast, LV$\operatorname{sh} T c t p 1$ transduction attenuated the glomerular hypertrophy

\section{b}
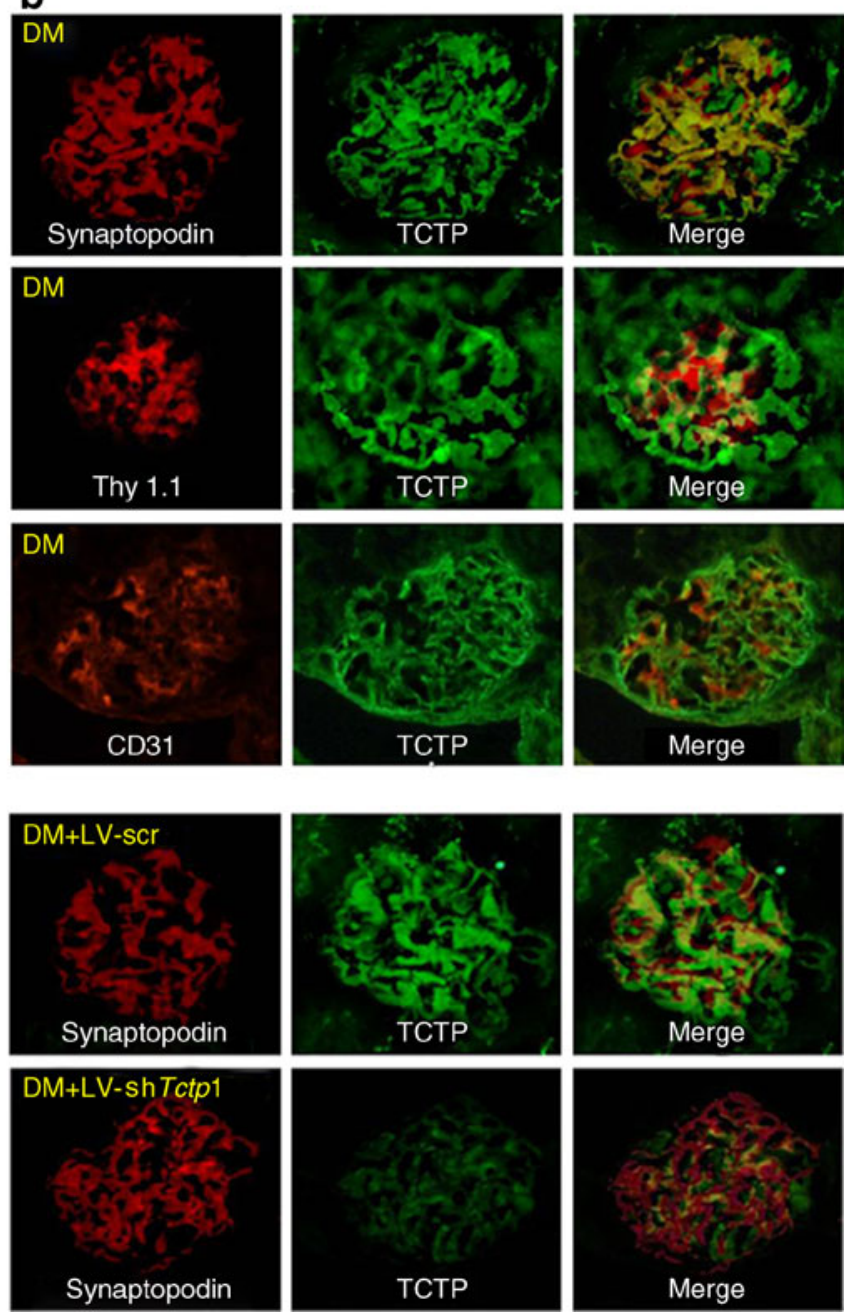

production was primarily attributable to the increase in podocytes. $\mathbf{c}$ Both TCTP fluorescence and the colocalisation signal (yellow) were decreased in $\mathrm{DM}+\mathrm{LV}$ shTctp 1 glomeruli, suggesting that the lentivirus-mediated RNA interference of TCTP effectively inhibited the diabetes-induced TCTP overproduction in podocytes. LV-scr had no effect on the production of TCTP (magnification $\times 400)$ 
in diabetic mice but did not change the size of glomeruli in control mice (Fig. 3a). The histological changes were then quantified with a stereological analysis. The mean $\mathrm{V}_{\mathrm{P}}$ and $\mathrm{V}_{\mathrm{G}}$

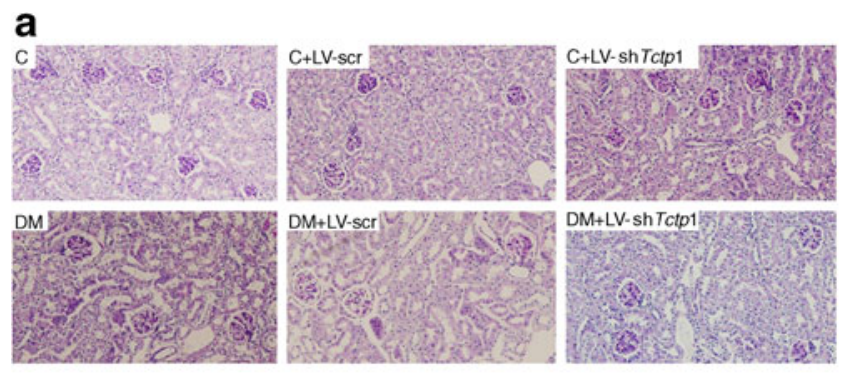

b
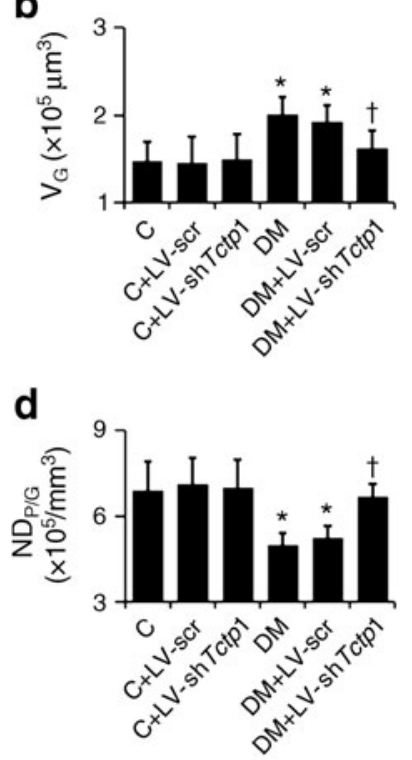

e

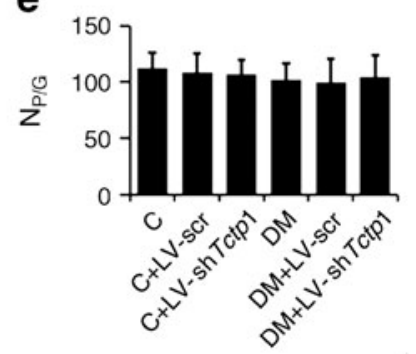

f
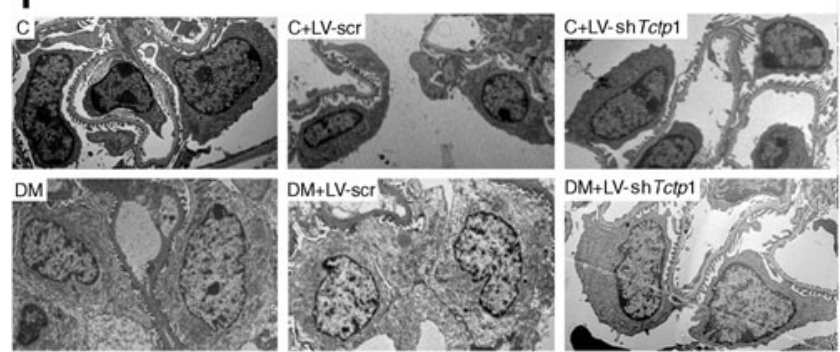

Fig. 3 Morphological changes of glomeruli and podocytes. a Representative light microscopy images of the kidneys. The kidneys from DM and $\mathrm{DM}+\mathrm{LV}$-scr mice exhibited marked glomerular hypertrophy compared with those of $\mathrm{C}$ or $\mathrm{C}+\mathrm{LV}$-scr mice, and treatment with $\mathrm{LV}$-shTctp 1 prevented this increase in DM mice (PAS stain; magnification $\times 100$ ) b-e Stereological analyses. The mean $\mathrm{V}_{\mathrm{G}}(\mathbf{b})$ and $\mathrm{V}_{\mathrm{P}}(\mathbf{c})$ were significantly higher, whereas $\mathrm{ND}_{\mathrm{P} / \mathrm{G}}(\mathbf{d}, \mathbf{e})$ was lower in the $\mathrm{DM}$ and $\mathrm{DM}+\mathrm{LV}$ scr groups. The LV-shTctp 1 treatment significantly ameliorated these morphological changes. On the other hand, the mean $\mathrm{N}_{\mathrm{P} / \mathrm{G}}$ was comparable among the six groups. ${ }^{*} p<0.05$ vs $\mathrm{C}$ and $\mathrm{C}+\mathrm{LV}$-scr groups; ${ }^{\dagger} p<$ 0.05 vs DM and DM+LV-scr group. $\mathbf{f}$ Representative transmission electron microscopy of glomeruli (magnification $\times 2,000$ ). Prominent hypertrophy of the podocytes was noted in DM and DM+LV-scr mice. The LV$\operatorname{sh} T c t p 1$ treatment substantially ameliorated the hypertrophy of the podocytes in DM mice. Data are means \pm SEM were significantly higher in $\mathrm{DM}$ and $\mathrm{DM}+\mathrm{LV}$-scr groups than in $\mathrm{C}$ and $\mathrm{C}+\mathrm{LV}$-scr groups, whereas the $\mathrm{ND}_{\mathrm{P} / \mathrm{G}}$ was lower in $\mathrm{DM}$ and $\mathrm{DM}+\mathrm{LV}$-scr groups. These morphological changes were significantly ameliorated by LV-shTctp 1 treatment. Meanwhile, LV-shTctp 1 transduction in control mice did not affect the $\mathrm{V}_{\mathrm{P}}$ or $\mathrm{V}_{\mathrm{G}}$. The $\mathrm{N}_{\mathrm{P} / \mathrm{G}}$ was not significantly different among the groups (Fig. 3b-e). Electron microscopy revealed that the podocytes of $\mathrm{DM}$ and $\mathrm{DM}+\mathrm{LV}$-scr mice were enlarged with thickening of the GBM and focal foot process effacement. However, diabetes-induced podocyte hypertrophy and foot process effacement, but not GBM thickening, were substantially attenuated in DM+LV-shTctp 1 mice (Fig. $3 \mathrm{f}$ and ESM Fig. 3).

Effect of TCTP inhibition on the mTORC1 effectors, CKIs and apoptosis The protein levels of phospho-4EBP1, phospho-p70S6K, p27 and p21 were significantly increased in $\mathrm{DM}$ and $\mathrm{DM}+\mathrm{LV}$-scr glomeruli, and LV-shTctp 1 transduction in diabetic mice significantly abrogated these increases. However, LV-shTctp 1 transduction in control mice did not affect the protein levels of the molecules. The protein levels of 4EBP1 and p70S6K were not different among the groups (Fig. 4a). There were significant increases in the numbers of TUNEL-positive cells in DM and DM+ LV-scr groups relative to C group, and this increase was significantly ameliorated by LV-shTctp 1 treatment in diabetic mice. Considering the location and appearance of TUNELpositive cells within glomeruli, podocytes were the main apoptotic cells. Meanwhile, LV-shTctp1 did not affect the number of TUNEL-positive cells in control mice (Fig. 4b).

Levels of plasma and urine TCTP There were no significant differences in plasma TCTP levels between DM and C mice. Moreover, LV-shTctp 1 treatment failed to reduce plasma TCTP levels in both $\mathrm{C}$ and DM mice. In contrast, urinary $\mathrm{TCTP} /$ creatinine ratios were significantly increased in DM mice compared with $\mathrm{C}$ mice, and these increases in DM mice were attenuated by LV-shTctp 1 transduction, but did not reach statistical significance (ESM Fig. 4).

Effect of TCTP inhibition on long-term renal alterations in $d b / d b$ mice At 28 weeks of age, the ratios of kidney/body weight in $d b / d b$ and $d b / d b+L V$-scr mice were significantly higher than in $d b / m$ and $d b / m+\mathrm{LV}$-scr mice, and this increase in $d b / d b$ mice was significantly abrogated by LV-shTctp1. In addition, compared with the $d b / m$ groups, 24-h AER was significantly higher in $d b / d b$ mice, and LV$\operatorname{sh} T c t p 1$ transduction significantly inhibited the increase in $d b / d b$ mice. Moreover, creatinine clearance normalised for body weight was significantly lower in $d b / d b$ and $d b / d b+$ LV-scr mice than $d b / m$ and $d b / m+L V$-scr mice. Although LV-shTctp 1 administration in $d b / d b$ mice ameliorated the decrease in creatinine clearance, there was no statistically 

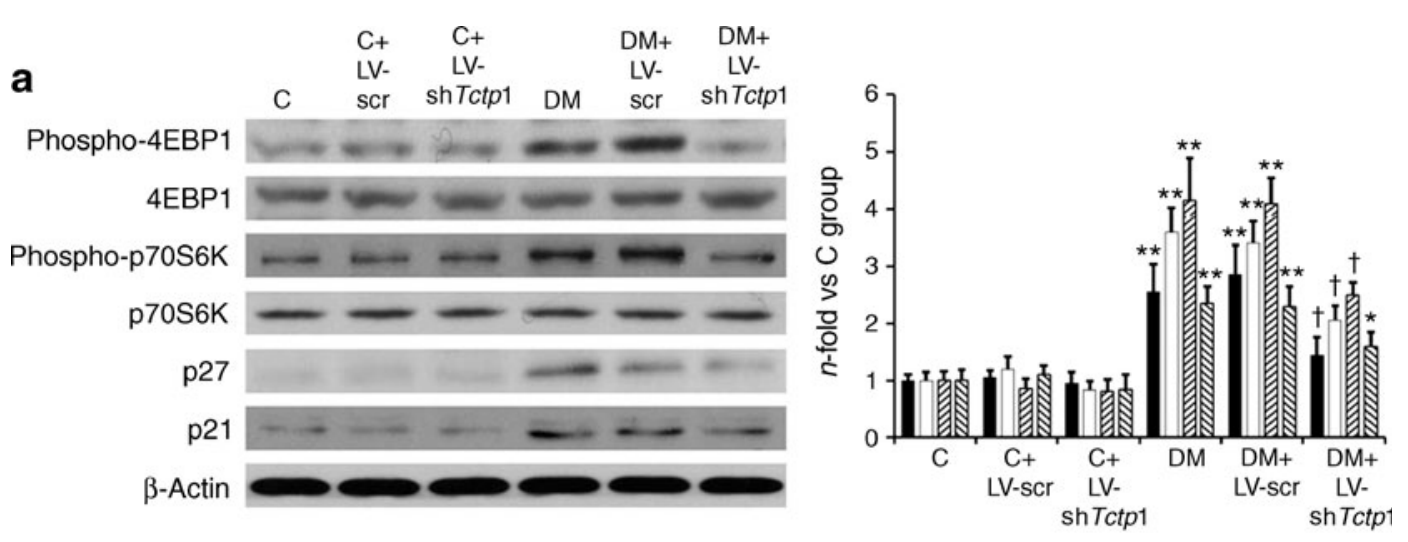

b
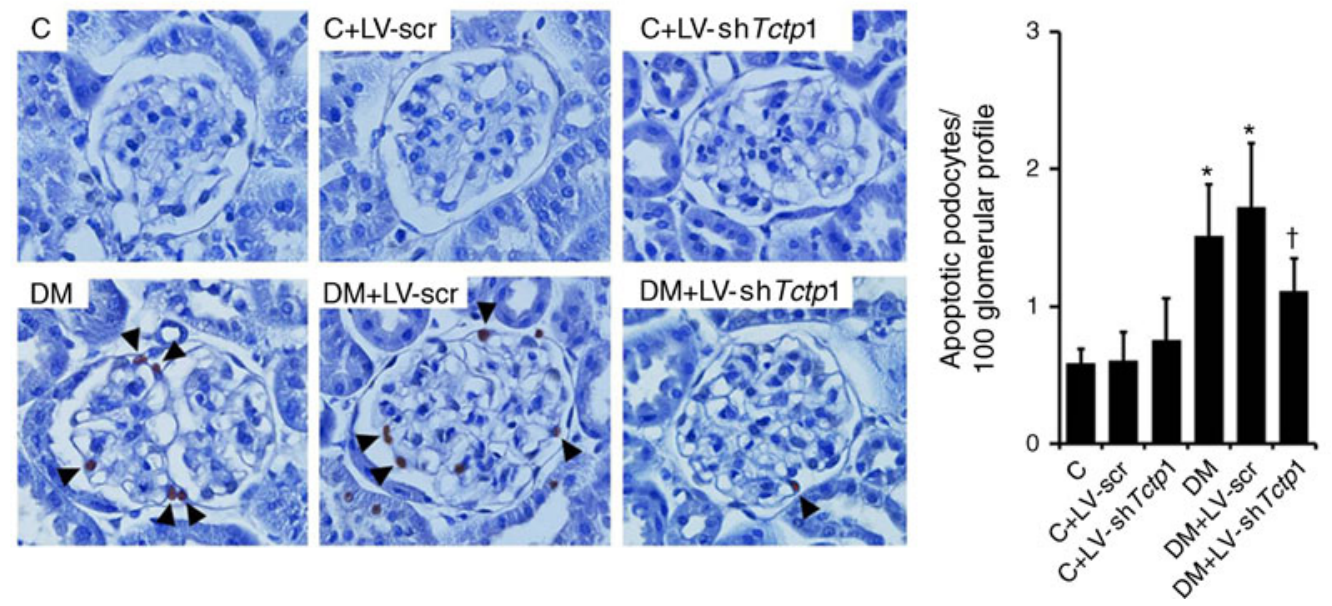

Fig. 4 Effect of TCTP inhibition on mTORC1 signalling, CKIs and apoptosis. a A representative western blot of glomerular phospho4EBP1, 4EBP1, phospho-p70S6K, p70S6K, p27 and p21 (representative of four blots). The ratios of phospho-4EBP1/4EBP1 and phosphop70S6K/p70S6K were significantly higher in DM and DM+LV-scr glomeruli, and the transduction of LV-shTctp 1 significantly attenuated these increases in 4EBP1 and p70S6K activation in DM glomeruli (by $43.1 \%$ and $43.0 \%$ respectively). Glomerular $\mathrm{p} 27$ and $\mathrm{p} 21$ protein production was significantly higher in DM mice than in $\mathrm{C}$ mice, and the administration of LV-shTctp 1 significantly reduced these increases. Densitometric quantification revealed 4.3 - and 2.5-fold increases in glomerular p27 and p21 protein production in DM vs C mice. LV-

significant difference (Table 2). Consistent with these functional data, mesangial expansion was observed in 28-week
shTctp 1 treatment blocked these increases by $39.8 \%$ and $32.2 \%$, respectively. Black bars, phospho-4EBP1/4EBP1; white bars, phospho-p70S6K/ p70S6K; upward diagonal hatched bars, p27/ $\beta$-actin; downward diagonal hatched bars, $\mathrm{p} 21 / \beta$-actin. ${ }^{* *} p<0.01$ vs $C$ groups; ${ }^{\dagger} p<0.01$ vs DM group; $* p<0.05$ vs DM group. b Assessment of podocyte apoptosis using the TUNEL assay. There was a significant increase in the mean number of TUNEL-positive podocytes (arrowheads) in DM and DM+LV-scr mice when compared with $\mathrm{C}$ and $\mathrm{C}+\mathrm{LV}$-scr mice. The increase in apoptotic podocytes in DM glomeruli was significantly abrogated by LV-shTctp1 treatment. Meanwhile, treatment with LV-shTctp 1 did not affect the number of TUNEL-positive podocytes in C mice (magnification $\times 400$ ). ${ }^{*} p<$ 0.05 vs $C$ groups; ${ }^{\dagger} p<0.05$ vs DM group. Data are means \pm SEM

$d b / d b$ and $d b / d b+$ LV-scr mice (Fig. 5a, b), along with increased glomerular mRNA and protein levels of fibronectin

Table 2 Animal data on $d b / m$ and $d b / d b$ mice at 28 weeks of age

\begin{tabular}{lllllll}
\hline Variable & $d b / m$ & $d b / m+\mathrm{LV}$-scr & $d b / m+\mathrm{LV}$-shTctp 1 & $d b / d b$ & $d b / d b+\mathrm{LV}$-scr & $d b / d b+\mathrm{LV}-\mathrm{sh} T c t p 1$ \\
\hline Body weight (g) & $29.4 \pm 1.1$ & $29.9 \pm 0.9$ & $28.1 \pm 1.2$ & $48.1 \pm 3.5^{* * *}$ & $48.9 \pm 4.1^{* * *}$ & $46.5 \pm 4.5^{* * *}$ \\
Kidney/body weight (\%) & $0.52 \pm 0.04$ & $0.49 \pm 0.04$ & $0.48 \pm 0.03$ & $0.80 \pm 0.09^{* * *}$ & $0.82 \pm 0.10^{* * *}$ & $0.61 \pm 0.08^{*}$ \\
Blood glucose (mmol/l) & $7.86 \pm 0.67$ & $7.73 \pm 0.57$ & $7.44 \pm 0.74$ & $33.09 \pm 2.37^{* * *}$ & $31.09 \pm 2.31^{* * *}$ & $32.09 \pm 2.84$ \\
24-h AER ( $\mu$ g/day) & $11.3 \pm 3.7$ & $14.2 \pm 3.0$ & $12.4 \pm 4.3$ & $360.1 \pm 31.3^{* * *}$ & $337.6 \pm 29.9^{* * *}$ & $181.2 \pm 21.6^{*}$ \\
Creatinine clearance $\left(\mu 1 \mathrm{~min}^{-1}\right.$ & $13.9 \pm 1.2$ & $13.8 \pm 1.3$ & $13.5 \pm 1.1$ & $7.4 \pm 0.8^{* * *}$ & $7.1 \pm 0.9^{* * *}$ & $9.0 \pm 1.0$ \\
$\quad$ g body weight] $^{-1}$ ) & & & & & \\
\hline
\end{tabular}

Data are mean $\pm \operatorname{SEM}(n=8$ per group)

${ }^{*} p<0.05$ vs $d b / d b$ mice; ${ }^{* * *} p<0.001$ vs $d b / m$ mice 
a

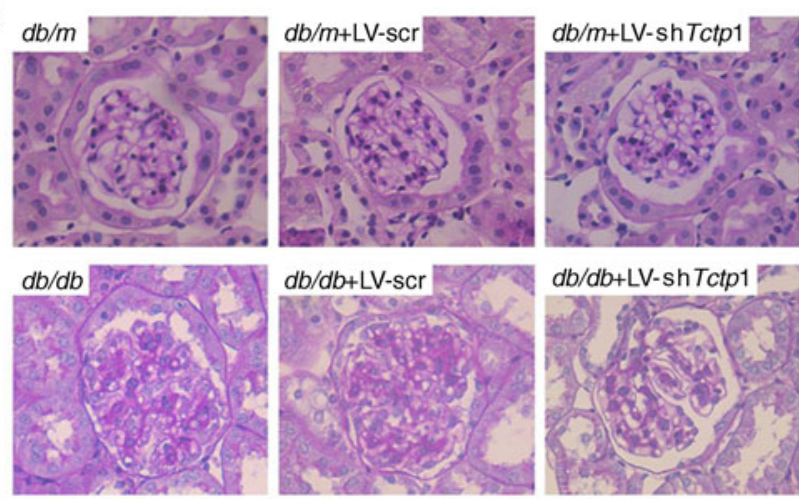

d
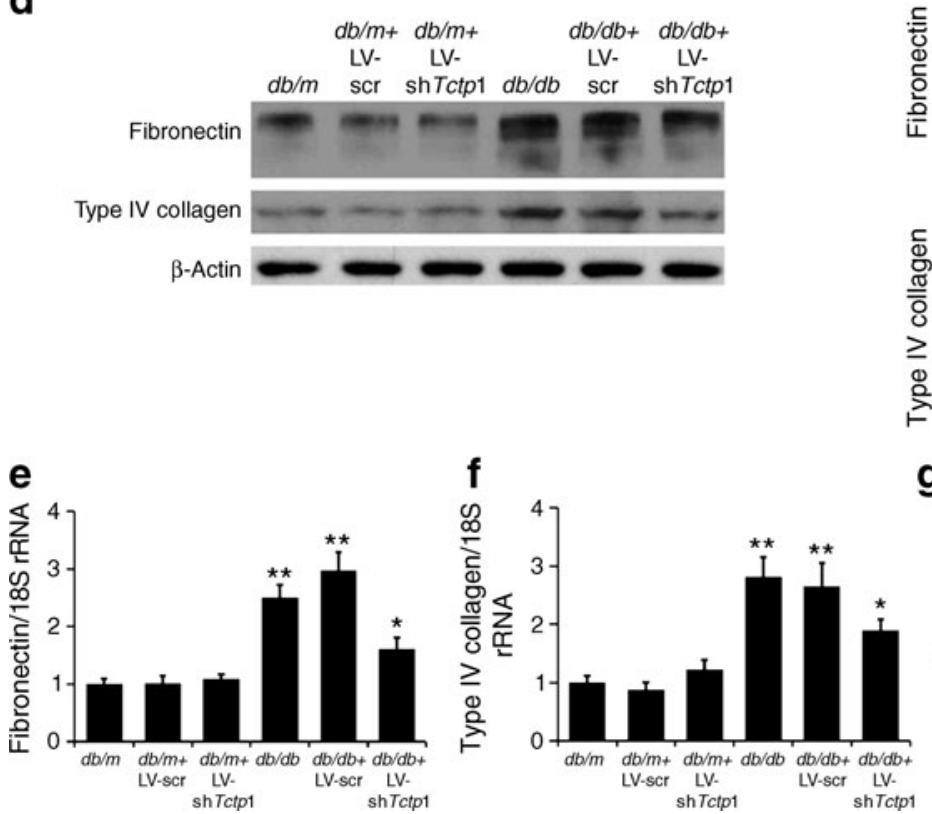

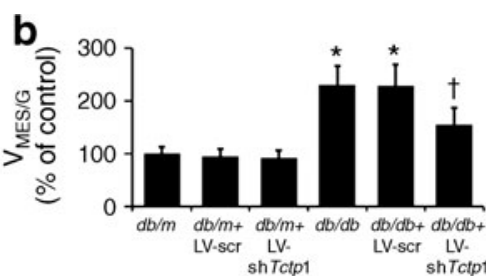

C
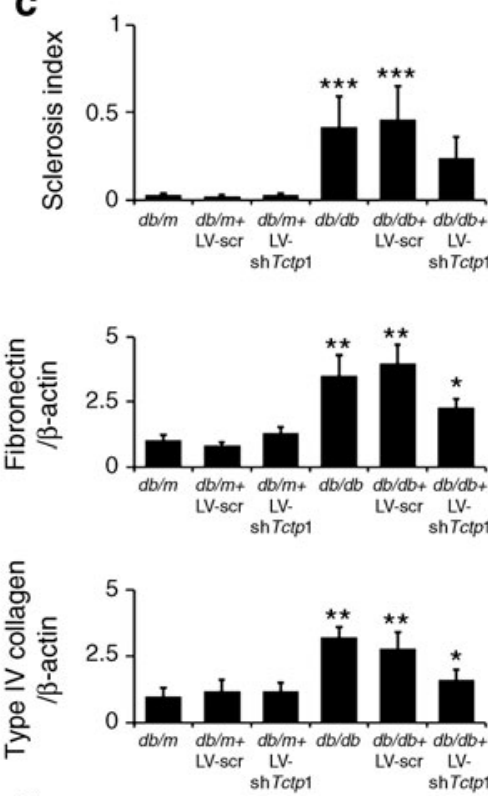

g

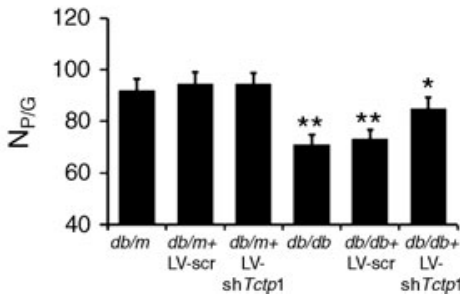

Fig. 5 Effect of TCTP inhibition on long-term renal alterations in $d b /$ $d b$ mice at 28 weeks of age. a, b Representative light microscopy images of PAS-stained kidney sections (a) and stereological analysis for mesangial volume (b). Enhanced mesangial expansion in $d b / d b$ mice was ameliorated by LV-shTctp 1 treatment (magnification $\times 400$ ). ${ }^{*} p<0.05$ vs $d b / m$ mice; ${ }^{\dagger} p<0.05$ vs $d b / d b$ mice. c Sclerosis index. Glomerulosclerosis was partly ameliorated in $d b / d b+\mathrm{LV}$-shTctp 1 mice. $* * * p<0.001 \mathrm{vs} d b / m$ mice. d A representative western blot of glomerular fibronectin and type IV collagen (representative of four blots). Glomerular fibronectin and type IV collagen protein production were significantly higher in $d b / d b$ and $d b / d b+\mathrm{LV}$-scr mice when compared with $d b / m$ and $d b / m+\mathrm{LV}$-scr mice, and LV-shTctp 1 treatment in $d b / d b$ mice significantly reduced the production of these proteins. ${ }^{*} p<0.05$ vs $d b / d b$ mice; ${ }^{* *} p<0.01$ vs $d b / m$ mice. The expression patterns of the fibronectin (e) and type IV collagen (f) mRNA were similar to those of the proteins. ${ }^{*} p<0.05$ vs $d b / d b$ mice; ${ }^{*} p<0.01$ vs $d b / m$ mice. g Stereological analysis for podocyte number. LV-shTctp 1 treatment significantly prevented the loss of podocytes in $d b / d b$ mice. ${ }^{*} p<0.05$ vs $d b / d b$ mice; ${ }^{* *} p<0.01$ vs $d b / m$ mice. Data are means \pm SEM and type IV collagen (Fig. 5d-f) and reduced podocyte number (Fig. $5 \mathrm{~g}$ ). These changes were significantly attenuated by LV-shTctp 1 administration. Furthermore, $d b / d b$ and $d b / d b+\mathrm{LV}$-scr mice displayed significantly increased sclerosis index, whereas LV-shTctp 1 administration in $d b / d b$ mice tended to decrease the score (Fig. $5 \mathrm{c}$ ).

Tctp mRNA and protein levels in cultured podocytes $\mathrm{HG}$ caused an increase in Tctp mRNA expression in a time- dependent manner. $\mathrm{NG}+\mathrm{AII}$ also significantly increased Tctp mRNA and protein levels in a time-dependent manner (Fig. 6a). Western blots of TCTP showed a pattern similar to that of mRNA expression (Fig. 6b). Meanwhile, L-158809, an AII receptor antagonist, significantly reduced HG-induced TCTP protein production (Fig. 6c), suggesting that increased TCTP levels in HG-stimulated podocytes is partly attributable to the increase in AII levels by HG. 


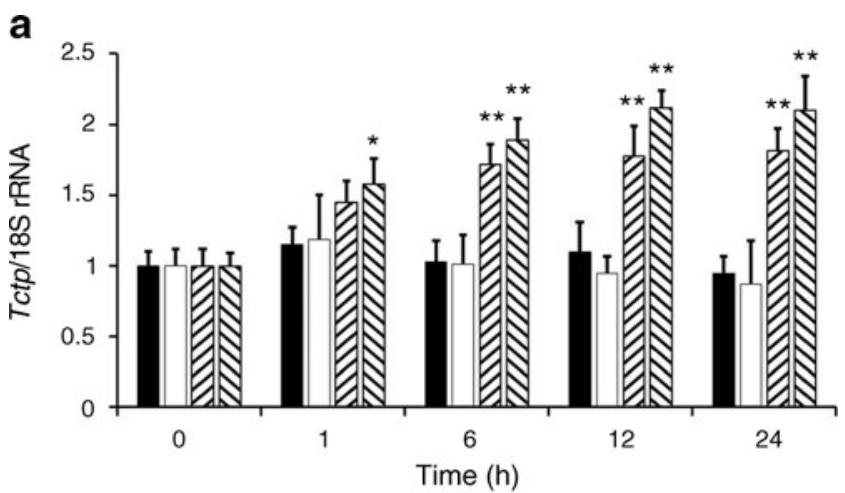

b
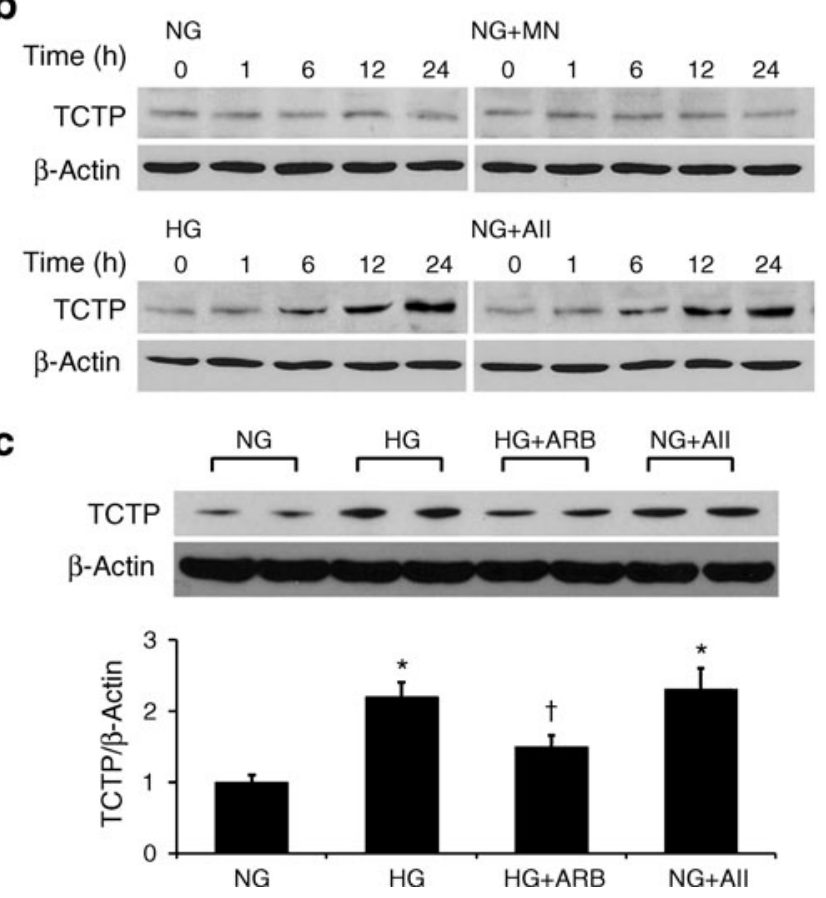

Fig. 6 Tctp mRNA and protein production in cultured podocytes. a, b Time course of Tctp mRNA (a) and protein production (b) in cultured podocytes. Tctp mRNA and protein production continued to increase over $24 \mathrm{~h}$ in $\mathrm{HG}$ - and NG+AII-treated podocytes, but not in $\mathrm{NG}$ or $\mathrm{NG}+\mathrm{MN}$ cells. Black bars, $\mathrm{NG}$; white bars, $\mathrm{NG}+\mathrm{MN}$; hatched bars, $\mathrm{HG}$; cross-hatched bars, NG+AII. $* p<0.05$ vs NG group at the same time point; ${ }^{* *} p<0.01$ vs NG group at the same time point. c A representative western blot of TCTP protein in cultured podocytes after $24 \mathrm{~h}$ exposure to $\mathrm{NG}, \mathrm{NG}+\mathrm{MN}, \mathrm{HG}, \mathrm{HG}+\mathrm{L}-158809$ (ARB) and $\mathrm{NG}+\mathrm{AII}$ (representative of four blots). HG- and NG+AII-stimulation significantly increased TCTP protein production in cultured podocytes and L-158809 significantly reduced the HG-induced TCTP protein production. Data are expressed as fold changes in Tctp mRNA and protein production relative to NG cells. ${ }^{*} p<0.05$ vs NG group; ${ }^{\dagger} p<0.05$ vs HG group. Data are means \pm SEM

Effect of TCTP inhibition on mTORC1 effectors, CKIs, apoptosis and hypertrophy in cultured podocytes LV-shTctp 1 treatment significantly abrogated the increase in Tctp mRNA and protein levels in HG-stimulated podocytes (Fig. 7a, b). HG significantly increased phospho-4EBP1, phospho-p70S6K and p27 protein levels, and the increases were significantly inhibited by LV-shTctp 1 . The protein levels of p21 showed a similar pattern to that of $\mathrm{p} 27$ but did not reach statistical significance. HG also significantly induced the protein production of active caspase-3, and LV-shTctp1 treatment in HG-stimulated podocytes significantly ameliorated this increase. Meanwhile, LV-shTctp 1 transduction in NG cells did not change the protein levels of mTORC1 effectors, CKIs or active caspase-3 (Fig. 7c).

The cellular protein content was significantly higher in HG-stimulated podocytes than in NG cells without significant change in cell number. The increase in protein/cell number under HG was significantly inhibited by LVshTctp1 (Fig. 8a). The relative cell size, determined by forward light scattering, was also significantly larger in HG-stimulated podocytes than in NG cells. LV-shTctp1 significantly reduced the cell size in HG-stimulated podocytes, but not in NG cells (Fig. 8b).

Effect of extracellular TCTP The TCTP levels in HGconditioned media were significantly higher than those in NG media (ESM Fig. 5a). We then performed additional experiments to clarify whether the changes in mTORC1 effectors, CKIs and cell size were attributed to secreted TCTP. However, rTCTP treatment in NG cells had no effect on the protein levels of mTORC1 effectors and CKIs, and the ratios of protein/cell number. In addition, the changes in protein levels of mTORC1 effectors, CKIs and cellular hypertrophy in HG-stimulated podocytes were not affected by dTBP2 (ESM Fig. 5b, c).

\section{Discussion}

TCTP is ubiquitously produced in a wide spectrum of cell types, with high levels of production in actively proliferating cells. In addition, TCTP is induced by growth signals, numerous cytokines and various stress conditions, including oxidative stress, heat shock and endoplasmic reticulum stress [25]. A recent proteomic analysis of cultured skin fibroblasts showed an upregulation of TCTP in patients with DN [26]. As cultured skin fibroblasts are a suitable cell model for investigating the mechanisms of DN development [27], the production pattern of TCTP was assumed to be similar in renal cells under diabetic conditions. As expected, we found increased TCTP levels in podocytes of DM glomeruli and in HG-stimulated cultured podocytes. Interestingly, AII also increased TCTP production, and HG-induced TCTP overproduction was ameliorated by ARB treatment. AII is locally produced in podocytes under diabetic conditions [28] and plays a pivotal role in the development of DN through oxidative stress, synthesis of various cytokines and induction of endoplasmic reticulum stress [29]. Most of these 
a

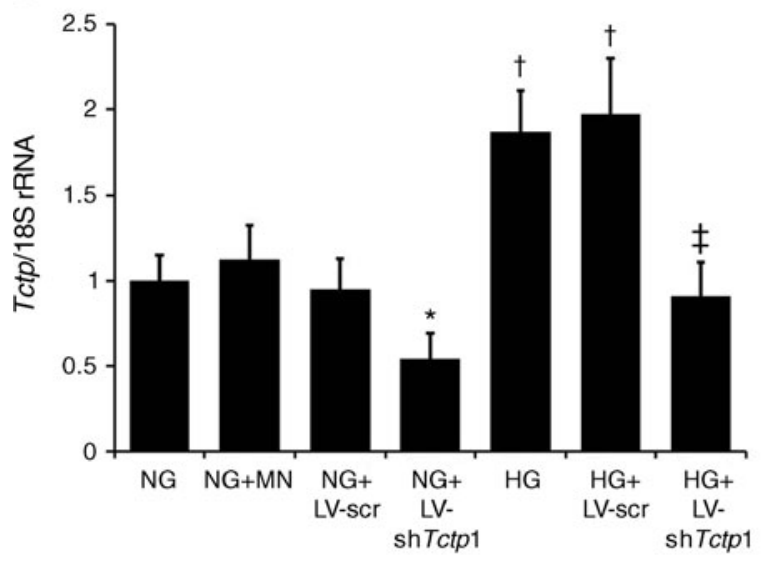

b

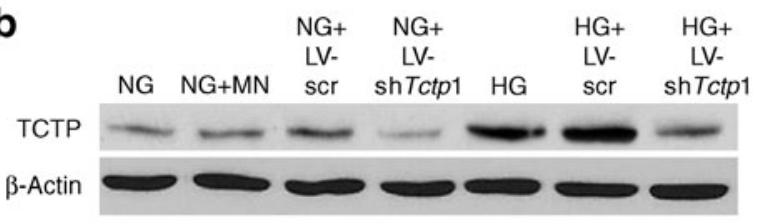

C
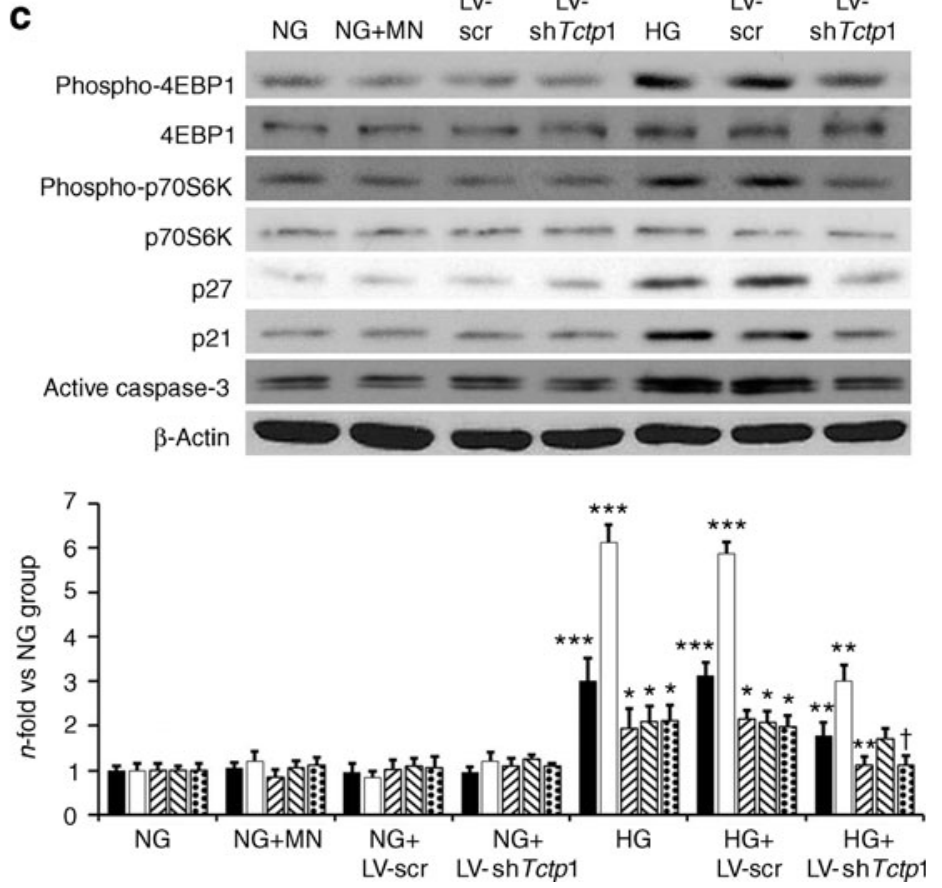

Fig. 7 Effect of TCTP knockdown on mTORC1 signalling, production of cell-cycle regulatory proteins, and apoptosis. a and b Genesilencing efficiency of LV-shTctp 1 in cultured podocytes. LV-shTctp 1 treatment significantly reduced the levels of Tctp mRNA (a) and protein (b) in NG- and HG-stimulated podocytes. ${ }^{*} p<0.05$ vs NG groups; ${ }^{\dagger} p<0.01$ vs NG groups; ${ }^{\star} p<0.01$ vs HG group. c A representative western blot of phospho-4EBP1, 4EBP1, phospho-p70S6K, p70S6K, p27, p21 and active caspase-3 in cultured podocytes (representative of four blots). The protein production levels of phospho4EBP1, phospho-p70S6K, p27 and active caspase-3 were significantly

conditions are mediated by AII overlap with the regulatory mechanisms for TCTP, suggesting that HG-induced AII may contribute to the increase in TCTP production in podocytes.

Recent investigations have revealed that TCTP activates the Akt and extracellular signal-regulated kinase (ERK) pathways $[12,30]$. The activated Akt or ERK pathway attenuates the tuberous sclerosis complex 1/2-mediated inactivation of Ras homologue enriched in brain (Rheb) [31], an immediate upstream regulator of mTORC1 [13, 14]. Furthermore, TCTP positively regulates the mTORC1 pathway by functioning as a guanine-nucleotide-exchange factor (GEF) for Rheb $[13,14]$. The GEF activity stimulates the exchange of GDP for GTP on Rheb, which in turn may directly activate mTORC1. Indeed, Hsu et al [14] demonstrated that TCTP knockdown in Drosophila reduces GTPbound Rheb as well as cell size and number. Taken together, these data suggest that TCTP may function upstream of mTORC1 through either direct or indirect activation of Rheb.

Although many studies have shown that mTORC1 is involved in glomerular hypertrophy [9, 32, 33], there has been limited evidence supporting the involvement of this higher in HG-stimulated podocytes, and these increases were significantly attenuated by LV-shTctp 1 . In contrast, there were no differences in $4 \mathrm{EBP} 1$ or $\mathrm{p} 70 \mathrm{~S} 6 \mathrm{~K}$ protein production among the groups. The protein production pattern of $\mathrm{p} 21$ was similar to that of $\mathrm{p} 27$, but the difference did not reach statistical significance. Black bars, phospho4EBP1/4EBP1; white bars, phospho-p70S6K/p70S6K; upward diagonal hatched bars, $\mathrm{p} 27 / \beta$-actin; downward diagonal hatched bars, $\mathrm{p} 21 /$ $\beta$-actin; black spotted bars, active caspase- $3 / \beta$-actin. ${ }^{*} p<0.05$ vs NG group $;{ }^{* *} p<0.01 \mathrm{vs} \mathrm{HG}$ group; ${ }^{* * *} p<0.001 \mathrm{vs} \mathrm{NG}$ group; ${ }^{\dagger} p<0.05$ vs HG group. Data are means $\pm \mathrm{SEM} \rightarrow$

pathway in podocyte hypertrophy in DN. However, recent studies have shown that mTORC1 effectors are upregulated in the podocytes of diabetic glomeruli, and podocytespecific mTORC1 inhibition attenuates not only diabetesinduced podocyte hypertrophy but also glomerulosclerosis $[10,34]$. These data suggest that the mTORC1 activation in podocytes may be an important step in the development and progression of DN. In agreement with previous studies, we found that the activity of mTORC1 effectors was increased in 6-week diabetic glomeruli, as was podocyte volume. However, despite this ample evidence for the aberrant mTORC 1 activation in podocytes under diabetic conditions, little is known about the signalling pathways regulating mTORC1 activity in the cells. In this study, we demonstrated that TCTP is differentially overproduced in podocytes of diabetic glomeruli, and TCTP inhibition attenuated proteinuria and podocyte hypertrophy that was accompanied by reduced phosphorylation of mTORC1 effectors in the early stage of a type $1 \mathrm{DN}$ model. Furthermore, we also found that TCTP inhibition in type 2 diabetic mice at an early age prevented the chronic changes of DN including mesangial expansion 


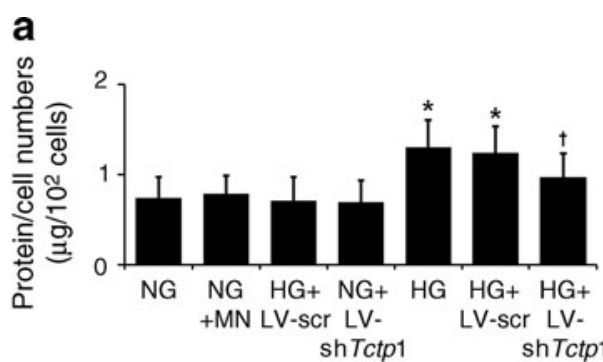

b
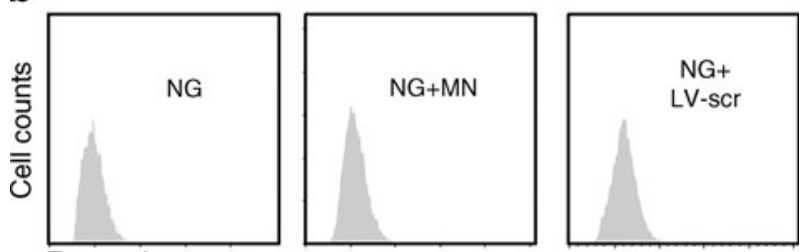

Forward scatter
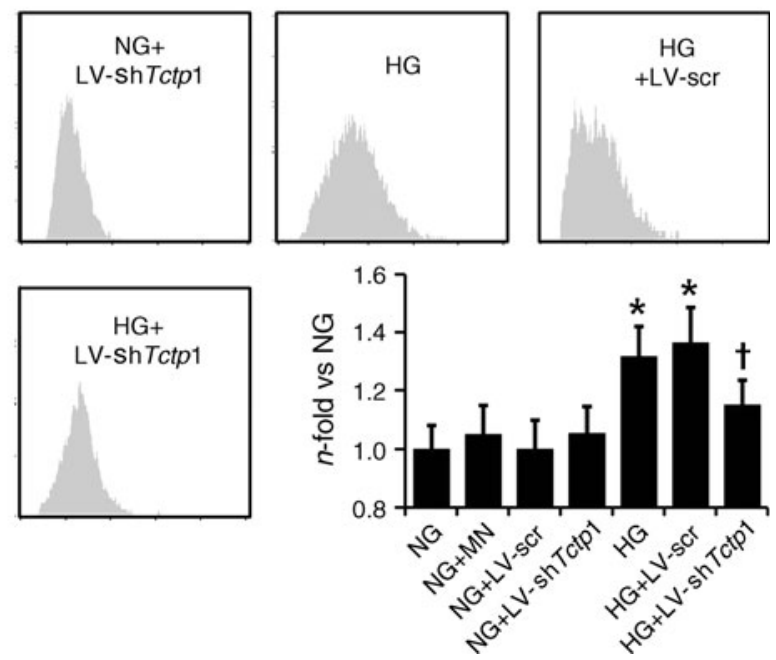

Fig. 8 Assessments of podocyte hypertrophy. a Protein/number of podocytes. A 1.91-fold increase in the protein/cell number ratio was observed in podocytes exposed to $\mathrm{HG}$, and the increase in the ratio was significantly inhibited (25.3\%) by LV-shTctp 1 . In contrast, LV-scr had no effect on the protein/cell number ratio in cultured podocytes exposed to NG. Data are means \pm SEM; ${ }^{*} p<0.05$ vs NG group; ${ }^{\dagger} p<0.05$ vs HG group. b A representative FACScan of the podocytes. The relative cell size, determined by mean forward light scattering, was $31.9 \%$ larger in HG-stimulated podocytes than in NG cells. LV-shTctp 1 significantly reduced the increase in the cell size of HG podocytes by $12.8 \%$. ${ }^{*} p<0.05$ vs NG group; ${ }^{\dagger} p<0.05$ vs HG group. Data are means \pm SEM

and glomerulosclerosis. These findings suggest that TCTP overproduction may contribute to diabetesinduced podocyte hypertrophy by stimulating mTORC 1 activity and that TCTP inhibition may have potential therapeutic roles in $\mathrm{DN}$.

Although the reasons for the differential production of TCTP in podocytes are unclear, it may be due to the difference in regulatory mechanisms of mTORC1 activity between podocytes and other glomerular cell types. Although the activity of Akt, a canonical upstream regulator of mTORC1, is increased in mesangial $[35,36]$ and endothelial cells [37] under diabetic conditions, the activity is decreased in podocytes from mice with early DN [38]. Indeed, reduced activity of Akt following impaired insulin signalling in podocytes is involved in the development of DN [39, 40]. Thus, these previous studies and our results indicate that a mechanism other than Akt activation may induce mTORC1 activation in podocytes under diabetic conditions, and TCTP overproduction in podocytes may play a role in Akt-independent mTORC1 activation. However, TCTP inhibition did not reproducibly reduce the activity of mTORC1 effectors in control mice, suggesting that TCTP does not regulate mTORC1 signalling under normal conditions or a minimum level of TCTP may be required to activate $\mathrm{mTORC} 1$ signalling.

Several studies support the existence of an interaction between the mTORC1 pathway and the production of CKIs. Sakaguchi et al [41] suggested that the renal production of CKIs in streptozotocin-induced diabetic mice is ameliorated by an mTORC1 inhibitor. Similarly, we found that increases in levels of CKIs in experimental diabetic glomeruli were attenuated by TCTP inhibition, which was accompanied by the reduced activities of mTORC1 effectors. These findings suggest that the mTORC1 pathway and its potential upstream activator, TCTP, may provoke cellular hypertrophy by inducing CKI production under diabetic conditions. In contrast, Hong et al [42] showed that activation of mTORC1 may promote $G_{1}$ progression through the cytoplasmic

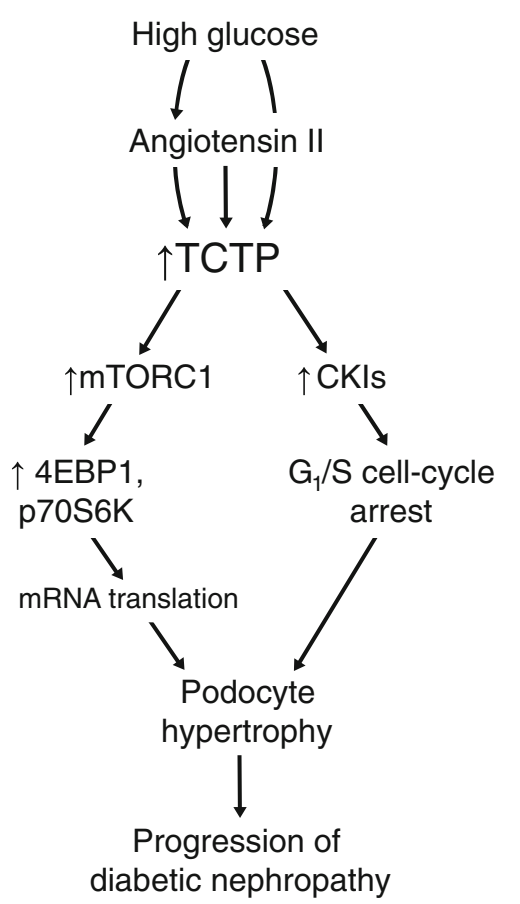

Fig. 9 A schematic representation that shows the outlined hypothesis 
mislocalisation of $\mathrm{p} 27^{\mathrm{Kip} 1}$. Moreover, several investigators reported that mTORC1 inhibitors block cell-cycle progression by disrupting cyclin/cyclin-dependent kinase complexes or upregulating p27 ${ }^{\mathrm{Kip} 1}$ [43]. We hypothesise that these opposite effects of mTORC1 on cell-cycle progression are largely due to the differences in the cell types and the diverse experimental conditions.

In addition to its growth-related function, TCTP was reported to have anti-apoptotic properties by antagonising the pro-apoptotic activity of Bax [44]. However, in this study, TCTP inhibition attenuated diabetes-induced podocyte apoptosis. Although the reason is unclear, one possible explanation is that podocyte apoptosis may be abrogated by the inhibition of the foregoing event, podocyte hypertrophy. Menini et al [45] demonstrated that podocyte apoptosis is not an early feature of experimental DN, as it is preceded by glomerular hypertrophy. In addition, Advani et al [46] found that inhibiting glomerular hypertrophy with an EGF receptor blocker preserves podocyte number in DM glomeruli. Moreover, a recent study showed that podocyte apoptosis occurs predominantly in hypertrophic glomeruli [47]. These findings support the thesis that hypertrophic process is a foregoing event of the apoptotic process. On the other hand, TCTP is differentially required for cell survival depending on the cell types, and its anti-apoptotic activity is more prominent in rapidly proliferating cells [48]. Therefore, TCTP may have little protective effect on apoptosis of terminally differentiated podocytes.

Besides its intracellular functions, TCTP is primarily secreted by mononuclear cells [49], and exhibits a cytokinelike activity that stimulates histamine release from basophils [25]. In this study, however, there was no difference in plasma TCTP levels between DM and C mice. In contrast, we found that the urine TCTP/creatinine ratios were significantly increased in DM compared with $\mathrm{C}$ mice, suggesting that the increase in glomerular TCTP production, but not plasma levels, may contribute to the increase in urinary TCTP concentrations in DM mice. However, as neither dTBP2 nor rTCTP affected the levels of mTORC1 effectors and CKIs, and the cell size, it can be surmised that cytosolic but not secreted TCTP is involved in podocyte hypertrophy.

In this study, we used a hydrodynamic delivery of shRNAproducing lentivirus to achieve a stable knockdown of the gene. Indeed, the EGFP was produced stably in kidney tissues throughout the 6 weeks of the study period, and LV-shTctp 1 transduction markedly reduced the colocalised signal for TCTP and synaptopodin. Although the method did not inhibit TCTP in podocytes specifically, these results suggest that this method can effectively silence the target in podocytes in vivo. In contrast, hydrodynamic injection of LV-shTctp 1 failed to reduce the plasma TCTP levels possibly due to the limited lifespan of the transduced mononuclear cells or the inefficient transduction of haematopoietic cells.
In conclusion, we demonstrated that TCTP production is increased in podocytes under diabetic conditions. In addition, the inhibition of TCTP attenuates the activation of the mTORC1 effectors and CKI production, and reduces podocyte hypertrophy. These findings suggest that TCTP may play an important role in the process of podocyte hypertrophy under diabetic conditions by stimulating mRNA translation and inducing cell-cycle arrest at the $\mathrm{G}_{1} / \mathrm{S}$ interphase (Fig. 9).

Acknowledgements We thank P. Osten (Northwestern University, Feinberg School of Medicine) for permission to use the lentivirus system, P. Mundel (University of Miami, Miller School of Medicine) for providing the mouse podocyte cell line and K. Lee (College of Pharmacy, Ewha Womans University, Seoul, Korea) for providing the dimerised TCTP-binding peptide.

Funding This work was supported in part by the Brain Korea 21 Project for Medical Sciences, Yonsei University, by the Korean Science and Engineering Foundation grant funded by the Korean government (R01-2007-000-20263-0), and by the National Research Foundation of Korea (NRF) grant funded by the Korea government (MEST) (No. 2011-0030711).

Duality of interest The authors declare that there is no duality of interest associated with this manuscript.

Contribution statement BYN, JJL, JTP, SHL, DHK, JYK, HYK, SHH, THY and DSH analysed data and revised the manuscript; DKK and SWK were responsible for the conception of the study and drafting the article. All authors approved the final version.

\section{References}

1. Wolf G, Ziyadeh FN (1999) Molecular mechanisms of diabetic renal hypertrophy. Kidney Int 56:393-405

2. Mundel P, Shankland SJ (2002) Podocyte biology and response to injury. J Am Soc Nephrol 13:3005-3015

3. Dalla Vestra M, Masiero A, Roiter AM, Saller A, Crepaldi G, Fioretto $\mathrm{P}$ (2003) Is podocyte injury relevant in diabetic nephropathy? Studies in patients with type 2 diabetes. Diabetes 52:1031-1035

4. Hudkins KL, Pichaiwong W, Wietecha T et al (2010) BTBR Ob/ $\mathrm{Ob}$ mutant mice model progressive diabetic nephropathy. J Am Soc Nephrol 21:1533-1542

5. Petermann AT, Pippin J, Durvasula R et al (2005) Mechanical stretch induces podocyte hypertrophy in vitro. Kidney Int 67:157-166

6. Wiggins JE, Goyal M, Sanden SK et al (2005) Podocyte hypertrophy, "adaptation," and "decompensation" associated with glomerular enlargement and glomerulosclerosis in the aging rat: prevention by calorie restriction. J Am Soc Nephrol 16:2953-2966

7. Herbach N, Schairer I, Blutke A et al (2009) Diabetic kidney lesions of GIPRdn transgenic mice: podocyte hypertrophy and thickening of the GBM precede glomerular hypertrophy and glomerulosclerosis. Am J Physiol Renal Physiol 296:F819-F829

8. Xu ZG, Yoo TH, Ryu DR et al (2005) Angiotensin II receptor blocker inhibits $\mathrm{p} 27^{\mathrm{Kip} 1}$ expression in glucose-stimulated podocytes and in diabetic glomeruli. Kidney Int 67:944-952 
9. Mori H, Inoki K, Masutani K et al (2009) The mTOR pathway is highly activated in diabetic nephropathy and rapamycin has a strong therapeutic potential. Biochem Biophys Res Commun 384:471-475

10. Godel M, Hartleben B, Herbach N et al (2011) Role of mTOR in podocyte function and diabetic nephropathy in humans and mice. $\mathrm{J}$ Clin Invest 121:2197-2209

11. Bommer UA, Borovjagin AV, Greagg MA et al (2002) The mRNA of the translationally controlled tumor protein P23/TCTP is a highly structured RNA, which activates the dsRNA-dependent protein kinase PKR. RNA 8:478-496

12. Kim M, Jung J, Lee K (2009) Roles of ERK, PI3 kinase, and PLC-c pathways induced by overexpression of translationally controlled tumor protein in HeLa cells. Arch Biochem Biophys 485:82-87

13. Dong X, Yang B, Li Y, Zhong C, Ding J (2009) Molecular basis of the acceleration of the GDP-GTP exchange of human Rheb by human TCTP. J Biol Chem 284:23754-23764

14. Hsu YC, Chern JJ, Cai Y, Liu M, Choi KW (2007) Drosophila TCTP is essential for growth and proliferation through regulation of dRheb GTPase. Nature 445:785-788

15. Dittgen T, Nimmerjahn A, Komai S et al (2004) Lentivirus-based genetic manipulations of cortical neurons and their optical and electrophysiological monitoring in vivo. Proc Natl Acad Sci U S A 101:18206-18211

16. Lois C, Refaeli Y, Qin XF, van Parijs L (2001) Retroviruses as tools to study the immune system. Curr Opin Immunol 13:496504

17. Bursill CA, McNeill E, Wang L et al (2009) Lentiviral gene transfer to reduce atherosclerosis progression by long-term CCchemokine inhibition. Gene Ther 16:93-102

18. Fleury S, Simeoni E, Zuppinger C et al (2003) Multiply attenuated, self-inactivating lentiviral vectors efficiently deliver and express genes for extended periods of time in adult rat cardiomyocytes in vivo. Circulation 107:2375-2382

19. El-Aouni C, Herbach N, Blattner SM et al (2006) Podocyte-specific deletion of integrin-linked kinase results in severe glomerular basement membrane alterations and progressive glomerulosclerosis. $\mathrm{J}$ Am Soc Nephrol 17:1334-1344

20. Fiala JC, Harris KM (2001) Extending unbiased stereology of brain ultrastructure to three-dimensional volumes. J Am Med Inform Assoc 8:1-16

21. Ma LJ, Nakamura S, Aldigier JC et al (2005) Regression of glomerulosclerosis with high-dose angiotensin inhibition is linked to decreased plasminogen activator inhibitor-1. J Am Soc Nephrol 16:966-976

22. Rops AL, van der Vlag J, Jacobs CW et al (2004) Isolation and characterization of conditionally immortalized mouse glomerular endothelial cell lines. Kidney Int 66:2193-2201

23. Mundel P, Reiser J, Zuniga Mejia Borja A et al (1997) Rearrangements of the cytoskeleton and cell contacts induce process formation during differentiation of conditionally immortalized mouse podocyte cell lines. Exp Cell Res 236:248-258

24. Kim M, Chung J, Lee $\mathrm{C}$ et al (2011) A peptide binding to dimerized translationally controlled tumor protein modulates allergic reactions. J Mol Med (Berl) 89:603-610

25. Bommer UA, Thiele BJ (2004) The translationally controlled tumour protein (TCTP). Int J Biochem Cell Biol 36:379-385

26. Tessari P, Puricelli L, Iori E et al (2007) Altered chaperone and protein turnover regulators expression in cultured skin fibroblasts from type 1 diabetes mellitus with nephropathy. J Proteome Res 6:976-986

27. LaPointe MS, Batlle D (2001) Cultured skin fibroblasts as an in vitro model to assess phenotypic features in subjects with diabetic nephropathy. Am J Kidney Dis 38:646-648

28. Yoo TH, Li JJ, Kim JJ et al (2007) Activation of the renin-angiotensin system within podocytes in diabetes. Kidney Int 71:1019-1027
29. Ziyadeh FN, Wolf G (2008) Pathogenesis of the podocytopathy and proteinuria in diabetic glomerulopathy. Curr Diabetes Rev 4:39-45

30. Jung J, Kim HY, Kim M, Sohn K, Lee K (2011) Translationally controlled tumor protein induces human breast epithelial cell transformation through the activation of Src. Oncogene 30:2264-2274

31. Laplante M, Sabatini DM (2009) mTOR signaling at a glance. J Cell Sci 122:3589-3594

32. Lee MJ, Feliers D, Mariappan MM et al (2007) A role for AMPactivated protein kinase in diabetes-induced renal hypertrophy. Am J Physiol Renal Physiol 292:F617-F627

33. Lloberas N, Cruzado JM, Franquesa M et al (2006) Mammalian target of rapamycin pathway blockade slows progression of diabetic kidney disease in rats. J Am Soc Nephrol 17:1395-1404

34. Inoki $\mathrm{K}$, Mori H, Wang $\mathrm{J}$ et al (2011) mTORC1 activation in podocytes is a critical step in the development of diabetic nephropathy in mice. J Clin Invest 121:2181-2196

35. Mahimainathan L, Das F, Venkatesan B, Choudhury GG (2006) Mesangial cell hypertrophy by high glucose is mediated by downregulation of the tumor suppressor PTEN. Diabetes 55:21152125

36. Wu D, Peng F, Zhang B et al (2009) PKC-beta1 mediates glucoseinduced Akt activation and TGF-betal upregulation in mesangial cells. J Am Soc Nephrol 20:554-566

37. Xin X, Khan ZA, Chen S, Chakrabarti S (2005) Glucose-induced Akt1 activation mediates fibronectin synthesis in endothelial cells. Diabetologia 48:2428-2436

38. Tejada T, Catanuto P, Ijaz A et al (2008) Failure to phosphorylate AKT in podocytes from mice with early diabetic nephropathy promotes cell death. Kidney Int 73:1385-1393

39. Coward RJ, Welsh GI, Yang J et al (2005) The human glomerular podocyte is a novel target for insulin action. Diabetes 54:3095-3102

40. Welsh GI, Hale LJ, Eremina V et al (2010) Insulin signaling to the glomerular podocyte is critical for normal kidney function. Cell Metab 12:329-340

41. Sakaguchi M, Isono M, Isshiki K, Sugimoto T, Koya D, Kashiwagi A (2006) Inhibition of mTOR signaling with rapamycin attenuates renal hypertrophy in the early diabetic mice. Biochem Biophys Res Commun 340:296-301

42. Hong F, Larrea MD, Doughty C, Kwiatkowski DJ, Squillace R, Slingerland JM (2008) mTOR-raptor binds and activates SGK1 to regulate p27 phosphorylation. Mol Cell 30:701-711

43. Paternot S, Roger PP (2009) Combined inhibition of MEK and mammalian target of rapamycin abolishes phosphorylation of cyclin-dependent kinase 4 in glioblastoma cell lines and prevents their proliferation. Cancer Res 69:4577-4581

44. Susini L, Besse S, Duflaut D et al (2008) TCTP protects from apoptotic cell death by antagonizing bax function. Cell Death Differ 15:1211-1220

45. Menini S, Iacobini C, Oddi G et al (2007) Increased glomerular cell (podocyte) apoptosis in rats with streptozotocin-induced diabetes mellitus: role in the development of diabetic glomerular disease. Diabetologia 50:2591-2599

46. Advani A, Wiggins KJ, Cox AJ, Zhang Y, Gilbert RE, Kelly DJ (2011) Inhibition of the epidermal growth factor receptor preserves podocytes and attenuates albuminuria in experimental diabetic nephropathy. Nephrology (Carlton) 16:573-581

47. Jung DS, Lee SH, Kwak SJ et al (2011) Apoptosis occurs differentially according to glomerular size in diabetic kidney disease. Nephrol Dial Transplant 2011. doi:10.1093/ndt/gfr301

48. Chen SH, Wu PS, Chou $\mathrm{CH}$ et al (2007) A knockout mouse approach reveals that TCTP functions as an essential factor for cell proliferation and survival in a tissue- or cell type-specific manner. Mol Biol Cell 18:2525-2532

49. Pasmans SG, Witteman AM, Aalbers M et al (1994) Variability of IgE-dependent histamine-releasing activity in supernatants of human mononuclear cells. Int Arch Allergy Immunol 103:44-52 